\title{
The Construction and Characteristics of Foreign Army's Electronic Countermeasure Equipment
}

\author{
Cuodong Zhang* \\ Naval Research Academy, Beijing 100161, China
}

\begin{abstract}
Based on the introduction of the development of electronic countermeasures, this paper introduces the composition, construction and application characteristics of foreign electronic countermeasures equipment, and puts forward some Suggestions on the development of electronic countermeasures.
\end{abstract}

Keywords: Foreign army, Electronic countermeasure equipment, Development of electronic countermeasures

\section{Introduction}

Electronic countermeasure, also known as foreign electronic, electronic warfare, the beginning is mainly used for launch on radio signals or using radio direction finding itself deceive signal is disturbed, practical use for the first time was in 1904, the Russian naval warfare, Russian shore-based radio and interfere with the Japanese success before a picket ship shelling guide communication, make it failed to reach a sneak attack.

The Vietnam War and the Middle East War developed the theory of systematic electronic countermeasures and formed the combat doctrine, and electronic countermeasures developed from "guarantee means" to an important "combat means" capable of carrying out offensive operations and dealing with precision-guided weapons.

The Gulf War is a significant sign of the development of system confrontation, and the application of electronic confrontation has reached an unprecedented scale and level, laying the battle idea of "taking electronic confrontation as the guide and running through the war" in modern war.

In the subsequent local wars, electronic confrontation played a more and more significant role, and its development attracted the attention of all countries. By early 2017, the US Department of Defense has released its first ELECTRONIC Warfare Strategy, which describes how the US Department of Defense will conduct electronic warfare and electromagnetic spectrum operations in a wider range. It not only provides strategic guidance for the US electronic warfare development, but more importantly, further promotes the establishment of electromagnetic spectrum independent operational areas.

\footnotetext{
* Corresponding author: $\underline{380055262 @ \text { qq.com }}$
} 


\section{System composition and characteristics}

In view of the most perfect and mature electronic countermeasures construction and actual combat application of the US military, which represents the highest development level of foreign countries, this paper takes the US military as an example to analyze the construction and application of foreign electronic countermeasures.

In March 1993, the department of defense staff, chairman of the joint meeting with memo (CJCS) form is issued policy documents, determine the electronic warfare are defined as the use of electromagnetic energy and orientation to control electromagnetic spectrum or attack any enemy military action, including electronic support (ES), electronic attack (EA) and electronic protection (EP) three main parts, according to the actual equipment system structure and application situation, should add operations support related parts.

\subsection{Electronic support}

Electronic reconnaissance has the advantages of long distance, wide coverage and strong identification ability. It can "conceal" the electromagnetic situation of naval battle field, collect electronic intelligence, and analyze the force dynamics and activity rules. It is the premise and basis for making operational planning and implementing effective interference. American military experts, when analyzing the reasons for winning the Gulf War, believe that "the most lethal weapon in the Gulf War is not missiles and fighter planes, nor warships and tanks, but the huge electronic reconnaissance and intelligence system deployed in the region". In the war, the americans the use of a large number of space-based power electronic reconnaissance, air and ground, including the invaders, magnum and so on more than 20 electronic reconnaissance satellites, eight EC - 130 - h, 28 EP - 3 e, 18 RC - 12, 9 RC - 135, $15 \mathrm{U}-2$ and so on electronic reconnaissance aircraft, 39 unmanned reconnaissance aircraft, etc., to build a seamless reconnaissance monitoring network, the real-time target detection, identification, interference by GPS, combat assessment plays an important role in such aspects. The electronic reconnaissance construction of the US army has two remarkable characteristics: "complete means" and "excellent intelligence" :

First, comprehensive means - means construction, pay attention to system application. With electronic reconnaissance satellites, electronic reconnaissance aircraft, unmanned aerial vehicles and reconnaissance ships as the core, the US military has built a complete reconnaissance, surveillance and intelligence collection system, which is capable of normalized reconnaissance, surveillance and continuous tracking of hot spots and sensitive events. If electronic reconnaissance satellites are vigorously developed, there are about 30 fourth-generation and some third-generation electronic reconnaissance satellites in service, which can be divided into low-orbit Marine surveillance satellites and synchronous orbit electronic reconnaissance satellites. The low-orbit ocean surveillance satellites, mainly "Baiyun" and its successor "space-based Wide area Surveillance system", cover the frequency band of $154 \mathrm{MHz} \sim 10 \mathrm{GHz}$. The multi-satellite network can locate the ships on the surface of the sea. The synchronous orbit electronic reconnaissance satellite is mainly "Magnum" and its subsequent "consultant". It covers the frequency band of $100 \mathrm{MHz} \sim$ $20 \mathrm{GHz}$ and adopts a large umbrella-like phased array reconnaissance antenna with a diameter of about 35 meters. The above satellites are mainly used to detect and receive ground radar, communications, missile telemetry and other signals, which have a great impact on electromagnetic security in our equipment tests, training exercises and other activities.

Second, the intelligence is fine - master fingerprint characteristics, to achieve individual identification. It pays attention to the acquisition of detailed intelligence, which is typical to collect fingerprint characteristics of radiation source, complete target individual identification, and be able to distinguish target platform number (such as ship's hull number) 
and individual. In the 1970s, the NAVAL Research Laboratory began to develop the radiation source individual identification Equipment (SEI). With the continuous funding and project support, the individual identification database was gradually integrated into the coastal, sea, air, sky and submarine electronic warfare equipment, and the individual identification database was subsequently established and continuously enriched to form the networked application capability. In 2002, the US military organized the "Millennium Challenge 2002" exercise for special verification.Before the exercise, SEI devices collected signal "fingerprint" features to build individual identification database; In the exercise, SEI devices from different platforms on shore, sea and air will transmit the detection and collection results to the command post, and integrate and identify individuals with the support of the database to form a unified and Shared electromagnetic situation and target situation, so as to realize cross-regional and continuous tracking and monitoring of the designated platform.

In terms of application, it pays attention to regular intelligence gathering, perceiving battlefield situation in wartime, detecting threat targets and guiding the implementation of interference or anti-radiation strike. In peacetime, reconnaissance finds unknown radiation sources, and deeply analyzes the acquisition of strategic and tactical information such as equipment performance, position and deployment, activity rules, usage characteristics, equipment system and development trend.

\subsection{Electronic attack}

When carrying out air penetration and attack missions, the US Navy aviation forces have formed and followed a basic principle: "No Fly without EA-6B electronic warfare aircraft"; In the Afghan war, the US Army chief of staff also declared that "the army will not fight in the war without 'compass call' (i.e. Ec-130h communication jamming aircraft)", which shows the role of electronic offensive force in the US military combat system. Usually in the war in advance, throughout the whole mission, such as the Gulf War air raid 15 minutes before, the US army carried out the "Snow" electronic warfare operation, sent EF-111A, EA-6B, EC$130 \mathrm{H}$ electronic warfare aircraft to carry out a comprehensive "electronic bombing" on the Iraqi deep radar network, communications system, cut off the Iraqi army's electronic "nerve", electronic "eyes and ears";After the air attack began, $\mathrm{f}-4 \mathrm{G}$ anti-radiation missile was sent to attack the aircraft companion and launch "Ham" anti-radiation missile for hard destruction while suppressing the interference of the Iraqi army's warning, detection and command and communication system.

Therefore, the US military attaches great importance to the development of electronic offensive equipment, and has built a complete equipment system including electronic warfare aircraft, a series of jamming pods, anti-radiation weapons and air launch bait. The main features are as follows:

The first is the coordinated development of soft interference and hard destruction. Heavily in the construction of EA - $18 \mathrm{~g}$ electronic warfare aircraft, the next generation of interference, pod (NGJ), and other soft interference power at the same time, enhance the anti-radiation strike capability, with the Italian air force joint AGM - 88 e advanced anti-radiation missile, improve the passive seeker, extension, increase of active millimeter wave terminal guidance radar reconnaissance distance, improve precision and ability to resist shutdown, resistance to movement.

Second, systematic development and application. By means of electronic warfare aircraft, air-launched decoy and missile-borne jammer, the system of force firepower penetration support jamming is constructed to form the whole combat process countermeasure capability combining the long-distance support jamming, the support jamming with the team, the close screen jamming and the platform self-defense jamming. 
Third, both peacetime and wartime. In normal times, there is a clear trend of normal application. Powerful electronic jamming capability can be used to interfere with the target of the other side's offshore and shore-based radiation sources, thus forming electromagnetic deterrence. For example, the south China Sea has repeatedly interfered with the radar of our observation stations and naval fleets.

\subsection{Electronic defense}

In response to the incoming threats, protect the security of the platform, the U.S. ships, aircraft and other platforms are equipped with perfect defensive electronic countermeasures, the battlefield threat warning, active passive comprehensive interference ability, such as surface ships equipped with SLQ - 32 electronic warfare system, passive SRBOC jamming equipment, outboard active decoy, card, part of the ship equipped with MK59 inflatable Angle reflector. The main features of electronic defense equipment construction of the US army are as follows:

First, to keep abreast of threats and continue to upgrade with advanced technologies. The typical is the SLQ-32 electronic warfare system. The system is equipped with nearly 200 sets of aircraft carriers, cruisers, destroyers and amphibious assault ships.To improve its ability to respond to new threats, the U.S. Military has launched the Spiral Upgrade Program (SEWIP), which "integrates advanced technologies and capabilities in an incremental manner, and on this basis achieves batch upgrades. "Upgrade is completed in two stages, including integrated emitter individual identification ability, increase the bait, card control function, improve the complex electromagnetic adaptability and direction finding accuracy, etc., has improved in the third stage, focus on developing jammer phased array system, improve the performance of active jamming, the defensive electronic countermeasures system has the capability of regional support interference.

Second, comprehensive and comprehensive use of means. In addition to the traditional inboard active jamming and outboard passive jamming, the surface ships are generally equipped with the "Nalka" outboard active decoy jointly developed by the United States and Australia, which USES vector rocket motors to achieve hovering and implement outboard active jamming against incoming missiles. In addition, according to the data, the americans in response to my new anti-ship missiles, emergency start electronic reconnaissance project sensitivity, expanding threat target's found that the low intercept system, at the same time, o burke class destroyer, emergency procurement with MK59 Mod0 inflatable Angle reflector, using 60 surface structure, to simulate ship false targets;Moreover development "warship extended range electronic warfare decoy", is a kind of quick launch unmanned aerial vehicle (uav) radar active decoy system, the system by the folding wings, booster rockets, electric drive system and electronic warfare equipment, equipped with electronic warfare equipment can be a long time, no crack and flexible response to incoming anti-ship missiles to implement electronic countermeasures.

\subsection{Combat support}

During the Vietnam War, the American A-6A attack aircraft alarm equipment was so deficient that the commander of the aircraft Wing said, "The wing is not fit to operate again until the problem is solved."To solve this problem, the Naval Air Command immediately organized experts to carry out intelligence data analysis, adjust the warning strategy, and verify the actual test flight in China Lake range, and finally the false alarm rate was reduced by $60 \%$. Since then, with the emergence of programmable electronic warfare equipment battlefield electromagnetic environment and increasingly complex, the U.S. military started to start preparing and interference strategy used to combat data for validation of electronic 
warfare combat support power construction, set up professional research department, to develop the corresponding equipment, the role of increasingly significant, so that the kosovo war, then Pacific fleet electronic attack forces commander John collier said, "no EA - 6 b, in kosovo, NATO is not the plane take off;The EA-6B will never take off without Crane.According to the characteristics of different types of ELECTRONIC warfare equipment, each type of ELECTRONIC warfare equipment of the U.S. Navy has corresponding tactical system support center, among which Crane branch is the ELECTRONIC warfare system support center of EA-6B, EA-18G and SLQ-32.The division has more than 4,000 active, off-duty civilian and contract employees, equipped with simulation LABS, hardware-in-the-loop simulation centers, and outfield verification firing ranges.

The MAIN functions of the US Army electronic Warfare Support system include target analysis and modeling, combat data generation and verification, jamming strategy optimization, electronic warfare mission planning, replay assessment and simulation training. The specific procedures are as follows:

One is to use the acquired battlefield intelligence to accurately grasp and evaluate the threat target and generate the target database.

The second is the programming and verification of combat data. According to the published electronic warfare target data, all electronic warfare equipment are simulated and tested to determine the effectiveness of the equipment.

Third, front - line data loading and combined application planning. According to operational tasks and combined with operational data, combat troops make operational plans and give full play to the maximum effectiveness of their equipment through effective technical and tactical coordination.

Fourth, strategy adjustment and loading. Field reprogramming of movable combat support equipment is used to adjust the equipment loading data in the light of battlefield emergencies. Fifthly, re-enactment analysis of all combat operations after the war. Analyze the effectiveness of confrontation and the rationality of equipment application, extract operational experience data, optimize and improve the data model and countermeasures.

\section{Revelations and suggestions}

\subsection{Constantly improve the electronic countermeasures equipment system centering on mission expansion and equipment technology development}

In view of the new demand for electronic countermeasures equipment, such as the transformation and development of the Navy, especially the far-sea mobile operations of the Navy's aircraft carrier formation, the defense of nansha islands and reefs, the deployment of overseas bases and the safeguarding of maritime rights and non-war military operations, etc. In the aspect of electronic reconnaissance, the emphasis should be given to the comprehensive processing of regional multi-source information and the networked application of individual identification of radiation sources. In the aspect of electronic attack, efforts should be made to construct the jamming system of maritime space-air information system and the jamming system of military firepower penetration support to comprehensively improve the electronic attack capability. In the field of electronic defense, the countermeasures should be supplemented to improve the ability to counter new threats, and electronic defense equipment should be developed systematically to meet the needs of ports, airports and other electronic defense. 


\subsection{Strengthen the study of main combat adversaries and improve the effectiveness of electronic countermeasures}

Different from radar and other sensor equipment, missile and other weapon systems, electronic countermeasures require specific targets, accurate timing, reasonable means and matching jamming styles, so as to achieve targeted reconnaissance jamming and achieve better countermeasure effectiveness. Therefore, it is not only necessary to fully grasp the technical characteristics of combat objects, such as parameter characteristics and working mode, but also to study their tactical characteristics, such as equipment performance, activity rules and application process, so as to effectively change the current situation that electronic countermeasures are not highly targeted and combat effectiveness is low.

\section{References}

1. J Guo, 60 cases of Electronic Warfare [M]. Beijing: PLA Press (2006)

2. L Lei, X Shi, LV Zeejun, et al. Reconnaissance and Surveillance - Clairance-Eye and Wind-Drift Ear in combat Space [M]. Beijing: National Defense Industry Press (2012)

3. Y Wang, S Zhu. International Electronic Warfare [J]. Electronic Information Control Laboratory (2017)

4. Y Mao. Analysis on improvement project of electronic warfare system of us navy surface ships [J]. Ship electronic engineering, 30, (2010)

5. Q L Xiong, Integrated Electronic Warfare -- The Killer Mace of information War [M]. Beijing: National Defense Industry Press (2008)

6. K J Liu. American Future Combat System [M]. Beijing: PLA Press (2006) 